\title{
Genomic and Physiological Characterization of Bacilli Isolated From Salt-Pans With Plant Growth Promoting Features
}

OPEN ACCESS

Edited by:

Sukhwan Yoon, Korea Advanced Institute of Science and Technology, South Korea

Reviewed by: Brent L. Nielsen,

Brigham Young University,

United States

Woo Jun Sul,

Chung-Ang University, South Korea

*Correspondence:

Rachele Isticato

isticato@unina.it

${ }^{t}$ These authors share first authorship

Specialty section:

This article was submitted to Microbiological Chemistry and

Geomicrobiology,

a section of the journal

Frontiers in Microbiology

Received: 27 May 2021

Accepted: 10 August 2021

Published: 13 September 2021

Citation:

Petrillo C, Castaldi S, Lanzilli M, Selci M, Cordone A, Giovannelli D and Isticato $R$ (2021)

Genomic and Physiological Characterization of Bacilli Isolated From Salt-Pans With Plant Growth Promoting Features.

Front. Microbiol. 12:715678. doi: 10.3389/fmicb.2021.715678

\author{
Claudia Petrillo ${ }^{1 \dagger}$, Stefany Castaldi ${ }^{1 \dagger}$, Mariamichela Lanzilli ${ }^{2}$, Matteo Selci ${ }^{1}$, \\ Angelina Cordone ${ }^{1}$, Donato Giovannelli ${ }^{1,3,4,5,6}$ and Rachele Isticato ${ }^{1,7 *}$
}

\begin{abstract}
'Department of Biology, University of Naples Federico II, Complesso Universitario Monte S. Angelo, Naples, Italy, ${ }^{2}$ Institute of Biomolecular Chemistry (ICB), CNR, Pozzuoli, Italy, ${ }^{3}$ National Research Council - Institute of Marine Biological Resources and Biotechnologies (CNR-IRBIM), Ancona, Italy, ${ }^{4}$ Department of Marine and Coastal Science, Rutgers University, New Brunswick, NJ, United States, ${ }^{5}$ Department of Marine Chemistry \& Geochemistry, Woods Hole Oceanographic Institution, Woods Hole, MA, United States, ${ }^{6}$ Earth-Life Science Institute, Tokyo Institute of Technology, Tokyo, Japan, ${ }^{7}$ Interuniversity Center for Studies on Bioinspired Agro-Environmental Technology (BAT Center), Portici, Italy
\end{abstract}

Massive application of chemical fertilizers and pesticides has been the main strategy used to cope with the rising crop demands in the last decades. The indiscriminate use of chemicals while providing a temporary solution to food demand has led to a decrease in crop productivity and an increase in the environmental impact of modern agriculture. A sustainable alternative to the use of agrochemicals is the use of microorganisms naturally capable of enhancing plant growth and protecting crops from pests known as PlantGrowth-Promoting Bacteria (PGPB). Aim of the present study was to isolate and characterize PGPB from salt-pans sand samples with activities associated to plant fitness increase. To survive high salinity, salt-tolerant microbes produce a broad range of compounds with heterogeneous biological activities that are potentially beneficial for plant growth. A total of 20 halophilic spore-forming bacteria have been screened in vitro for phyto-beneficial traits and compared with other two members of Bacillus genus recently isolated from the rhizosphere of the same collection site and characterized as potential biocontrol agents. Whole-genome analysis on seven selected strains confirmed the presence of numerous gene clusters with PGP and biocontrol functions and of novel secondary-metabolite biosynthetic genes, which could exert beneficial impacts on plant growth and protection. The predicted biocontrol potential was confirmed in dual culture assays against several phytopathogenic fungi and bacteria. Interestingly, the presence of predicted gene clusters with known biocontrol functions in some of the isolates was not predictive of the in vitro results, supporting the need of combining laboratory assays and genome mining in PGPB identification for future applications.

Keywords: spore-forming bacteria, biocontrol agents, halophiles, plant-growth-promoting bacteria, genome mining, Bacilli 


\section{INTRODUCTION}

In the past decades, social concern about the environmental effects of the uncontrolled use of chemical pesticides, fertilizers, and herbicides in the agricultural field has risen considerably. The use of chemicals for the protection and enhancement of crops has led to several negative consequences: the formation of stable phytopathogenic variants, the reduction in the number of beneficial microorganisms, and the accumulation of toxic substances in soils and aquatic ecosystems (Reddy et al., 2009; Pertot et al., 2017). Given the increased global demand for crop production, researchers and industries are seeking new, more sustainable and greener approaches to pesticides and fertilizers (Glick et al., 2007). In this framework, the use of microorganisms known as Plant-Growth-Promoting Bacteria (PGPB) for crop production appears to be a promising alternative. PGPB improve crop fitness and yields both, through direct and indirect mechanisms. Direct mechanisms include the promotion of alternative nutrient uptake pathways, through the solubilization of phosphorus, the fixation of atmospheric nitrogen, the acquisition of iron by siderophores, and the production of growth hormones and molecules like vitamins, amino acids, and volatile compounds (Babalola, 2010). Indirect mechanisms instead, include the prevention or reduction of the damage induced by phytopathogens through the production of different classes of antimicrobial compounds such as hydrolytic enzymes that can lyse a portion of the cell wall of many pathogenic fungi (Jadhav et al., 2017).

The work presented here is part of a wide study aimed at identifying and selecting halophilic Bacilli with potential applications as biofertilizers or biocontrol agents. For this purpose, samples from the rhizosphere of the nurse plants Juniperus sabina and nearby soils were collected from salt-pans (Castaldi et al., 2021). Nurse plants, such as J. sabina, exert beneficial effects on their surrounding ecosystem, facilitating the growth and development of other plant species. This positive effect is in part due to the plant influence on the composition of soil microbial communities, generally selecting for microorganisms capable of mineralizing nutrients, enhancing soil fertility, and thus promoting plant growth and health (Hortal et al., 2013; Goberna et al., 2014; Rodríguez-Echeverría et al., 2016). For this reason, the nurse-plants rhizosphere and relative surrounding soil are a useful source of PGPB. In addition, bacteria growing in extreme environments, like saltpans, have developed complex strategies to survive harsh conditions, which include the production of an array of diverse compounds, such as antioxidant pigments, lytic enzymes, and antimicrobial compounds, making them interesting biotechnological targets (Anwar et al., 2020). Among the PGPB, bacteria belonging to the Bacillus genus are of particular interest given their resistance to stressful environments and conditions due to their capacity of producing spores (Pesce et al., 2014), together with the ability to release a broad spectrum of secondary metabolites, the easy genetic manipulation, and the great ability to colonize plant surfaces (Kumar et al., 2011). In addition, the effectiveness of halo-tolerant Bacillus spp. to increase the growth of various crops under salt stress conditions has been widely reported (Shultana et al., 2020). Recently, we have identified and characterized PGPB Bacillus strains isolated from the rhizosphere of J. sabina (Castaldi et al., 2021). The two strains, named as Bacillus sp. RHFS10 and Bacillus sp. RHFS18, emerged for their promising PGP traits. These strains produce siderophores and solubilize phosphorus, enhancing plant nutrients uptake, and secrete indoleacetic acid (IAA), a phytohormone playing a key role in both root and shoot development. Additionally, both isolates showed a strong biocontrol activity, inhibiting the fungal phytopathogen Macrophomina phaseolina growth (Castaldi et al., 2021).

Here, we present the results of the screening of 20 halophilic Bacilli isolated from salt-pan sand samples. All the strains were characterized for PGP traits and five strains emerged for their high potentiality as biofertilizers and biocontrol agents. Comparative genomic analysis of the five sand strains and the previously characterized rhizospheric strains RHFS10 and RHFS18 revealed the presence of known genes involved in plant growth promotion and protection, sustaining, in part, the activities observed in vitro. Overall, this work suggests a strategy for the selection of potential PGP candidates belonging to Bacillus genus using combined in silico and in vitro approaches.

\section{MATERIALS AND METHODS}

\section{Isolation of Bacteria}

Bacillus strains used in this study were isolated from sand samples collected in the proximity of J. sabina plants growing in the salt-pans of Formentera (Spain). Sand samples were heat-treated at $80^{\circ} \mathrm{C}$, for $15 \mathrm{~min}$ to kill vegetative cells and select for spore-forming bacteria, and $1 \mathrm{~g}$ of sample was suspended in $9 \mathrm{ml}$ of TY broth $(10 \mathrm{~g} / \mathrm{L}$ tryptone, $5 \mathrm{~g} / \mathrm{L}$ yeast extract, and $8 \mathrm{~g} / \mathrm{L} \mathrm{NaCl}$ ) and 10 -fold serial dilutions placed on TY plates (Cangiano et al., 2010). After 4-5 days of incubation at $30 \pm 1{ }^{\circ} \mathrm{C}$, colonies were recovered and streaked on fresh TY plates, and pure cultures stored at $-80^{\circ} \mathrm{C}$ into glycerol stocks (Giglio et al., 2011).

\section{Phenotypic Characterization and Growth Conditions}

The phenotypic variants of isolated strains were determined by visual inspection. The facultative anaerobic growth was determined using the AnaeroGen sachets (Unipath Inc., Nepean, Ontario, Canada) placed in a sealed jar with bacteria streaked on TY agar plates and incubated at $37^{\circ} \mathrm{C}$ for 3 days. To confirm the sporulation ability, the bacteria were grown in Difco sporulation medium $\left(8 \mathrm{~g} / \mathrm{L}\right.$ Nutrient broth No. $4,1 \mathrm{~g} / \mathrm{L} \mathrm{KCl}, 1 \mathrm{mM} \mathrm{MgSO}{ }_{4}$, $1 \mathrm{mM} \mathrm{Ca}\left(\mathrm{NO}_{3}\right)_{2}, 10 \mu \mathrm{M} \mathrm{MnCl}_{2}$, and $1 \mu \mathrm{M} \mathrm{FeSO}_{4}$, Sigma-Aldrich, Germany) at $37^{\circ} \mathrm{C}$ for $30-48 \mathrm{~h}$, and the presence of spores was checked by light microscopy. Salt, $\mathrm{pH}$, and temperature tolerance were determined as follows: about $50 \mu \mathrm{l}$ of culture of each isolate grown in TY broth for $6 \mathrm{~h}$ at $37^{\circ} \mathrm{C}\left(10^{7}\right.$ cells $\left./ \mathrm{ml}\right)$ were transferred to individual tubes containing $5 \mathrm{ml}$ of TY broth with different $\mathrm{pH}(2.0,4.0,6.0,7.0,8.0,10.0$, and 12.0$)$ or $\mathrm{NaCl}$ concentration $(0,5,10,13,15$, and $18 \%)$ and left to grow at $37^{\circ} \mathrm{C}$ with agitation (Cangiano et al., 2014) . The temperature tolerance 
of isolates was tested incubating the cultures at 37 (control), $4,15,25,50$, and $60^{\circ} \mathrm{C}$. The growth (+) or no growth (-) in comparison with the controls after $24-48 \mathrm{~h}$ was recorded.

\section{Plant Growth-Promoting Traits Phosphate Solubilization}

The phosphate solubilization activity was evaluated by spot inoculation of $3 \mu \mathrm{l}$ of the freshly grown bacterial culture $\left(10^{7}\right.$ cells/ml) onto Pikovaskya's agar medium (Pikovskaya, 1948). The plates were incubated at $28^{\circ} \mathrm{C}$ for 10 days. The formation of transparent zones around the bacterial colonies indicates a positive result (Schoebitz et al., 2013).

\section{Siderophores Production}

The siderophores production was determined by the Chrome Azurol S (CAS) assay as described by Pérez-Miranda et al. (2007). Three milliliter of freshly-grown bacterial cultures was spot-inoculated on CAS agar plates and incubated at $28^{\circ} \mathrm{C}$. The formation of a yellow-orange halo zone around the bacterial colony was a positive indicator of siderophore production and the halo zone diameters were measured after 4 days of incubation.

\section{Indoleacetic Acid Detection}

The indoleacetic acid production was measured as described by Etesami et al. (2014), with some modifications. Briefly, each strain was cultured in $10 \mathrm{ml}$ of TY broth at $37^{\circ} \mathrm{C}$ for 4 days with shaking at $150 \mathrm{rpm}$. Following growth, $1 \mathrm{ml}$ of bacteria supernatant was mixed with $2 \mathrm{ml}$ of Salkowski reagent $\left(0.5 \mathrm{M} \mathrm{FeCl}_{3}\right.$ in $35 \% \mathrm{HClO}_{4}$ solution), and the solution was vortexed and incubated at room temperature for $30 \mathrm{~min}$. The formation of pink color was considered a positive reaction (Damodaran et al., 2013). Quantitative estimation of IAA $(\mu \mathrm{g} / \mathrm{ml})$ was obtained by recording spectroscopic absorbance at $535 \mathrm{~nm}$ using a standard curve prepared separately with pure IAA (Sigma) in the range $0-100 \mu \mathrm{g} / \mathrm{ml}$ (Gordon and Weber, 1951). Sterile TY medium was used as control.

\section{Biofilm Production and Swarming Motility}

To detect the ability to produce biofilm, bacterial isolates were grown in 24-well culture plates in TY broth for $48 \mathrm{~h}$ without agitation at $37^{\circ} \mathrm{C}$ in according to O'Toole (2011). Then, the supernatant was discarded, adhered cells were rinsed three times with distilled water and $1 \mathrm{ml}$ of a $0.1 \%$ crystal violet (CV) solution was added to stain the adhered biomass. Plates were incubated for $30 \mathrm{~min}$ at room temperature, washed carefully three times with distillated water and patted dry. Dye attached to the wells was extracted with $1 \mathrm{ml}$ of $70 \%$ ethanol and quantified at an absorbance of $570 \mathrm{~nm}$. Data were normalized by total growth estimated by OD600 $\mathrm{nm}$, and the experiment was performed in triplicate.

Swarming motility was tested according to the method adopted by Adler (1966). TY agar $0.7 \%$ plates were spot inoculated with $3 \mu \mathrm{l}$ of the freshly grown bacterial culture $\left(10^{7}\right.$ cells $/ \mathrm{ml}$ ). After an overnight incubation at $37^{\circ} \mathrm{C}$, the swarm diameters were measured.

\section{Whole-Genome Sequencing of the Selected PGPB}

DNA extraction was performed using the DNeasy PowerSoil kit (Qiagen, Hilden, Germany) according to the manufacturer's instructions. Genome sequencing was performed by MicrobesNG (Birmingham, United Kingdom) with the genomic DNA library prepared using the Nextera XT library prep kit (Illumina) following the manufacturer's protocol. Libraries were sequenced on the Illumina HiSeq using a $250 \mathrm{bp}$ paired-end protocol. Reads were adapted and trimmed using Trimmomatic 0.30 with a sliding window quality cutoff of Q15 (Bolger et al., 2014) and the de novo genome assembly was carried out with SPAdes (version 3.7) via MicrobesNG. Genomes were annotated using Prokka (Seemann, 2014). Biosamples accession numbers for strains RHFB, RHF2, RHF6, RHF12, RHF15, RHS10, and RHFS18 are, respectively: SAMN17389615, SAMN17389609, SAMN17389610, SAMN17389612, SAMN17389613, SAMN17389611, and SAMN17389614. MIGS compliant details regarding each genome are available in the Supplementary Table S1.

Average Nucleotide Identity (ANI) values between the sequenced genomes and the closest bacterial species identified from the 16S rRNA phylogenetic analysis (see below) were obtained using the OrthoANI algorithm of EZBioCloud (Yoon et al., 2017). An ANI similarity of $95 \%$ was considered as a cut-off for species delineation.

\section{Phylogenetic Analysis}

The 16S rRNA genes were extracted from the sequenced genomes using Anvio v2.3.3 (Eren et al., 2021). and compared to 76 reference $16 \mathrm{~S}$ rRNA genes from closely related strains identified using the Genome Taxonomy Database (GTDB) ${ }^{1}$ taxonomy and retrieved from the NCBI database. All sequences were aligned using Seaview 4.4.0 software (Corrado et al., 2021), and the phylogenetic tree was constructed using the Maximum-likelihood algorithm with model GTR+I+G4. Statistical support was evaluated by the approximate likelihoodratio test (aLRT) and is shown at the corresponding nodes of the tree. Clostridium difficile is used as an outgroup to root the tree.

\section{Evaluation of Potential Biocontrol Activity}

Isolated bacterial strains were tested in vitro for growth inhibitory activity against phytopathogenic fungi and bacteria are listed in Table 1. The phytopathogenic fungi are deposited in the fungal culture collection of the Plant Pathology Department of the University of Buenos Aires (FAUBA, Argentina) and were kindly supplied by Marcelo Anibal Carmona (Facultad de Agronomía, Cátedra de Fitopatología, Universidad de Buenos Aires, Buenos Aires, Argentina), except for Stemphylium vesicarium. All the fungi were stored on Potato Dextrose Agar (PDA) in Petri dishes. Dual-culture plate method was carried out to detect the antifungal activity in accordance with $\mathrm{Xu}$ and Kim (2014). Briefly, fungal plugs of $6 \mathrm{~mm} \times 6 \mathrm{~mm}$ diameter were placed at the center of PDA plates and $5 \mu$ of bacterial 
TABLE 1 | List of the phytopathogenic fungi and bacteria used in this study.

\begin{tabular}{|c|c|c|c|c|}
\hline Pathogen type & Species & Strain & Provenience & Host plant \\
\hline \multirow[t]{5}{*}{ Fungi } & Macrophomina phaseolina & $2,012,013-1$ & Argentine & Soy \\
\hline & Colletotrichum truncatum & $17-5-5$ & Argentine & Soy \\
\hline & Drechslera teres & $\mathrm{FT}$ & Argentine & Barley \\
\hline & Cercospora nicotianae & Ck_2017_B35 & Bolivia & Soy \\
\hline & Stemphylium vesicarium & & Italy & Pear \\
\hline \multirow[t]{7}{*}{ Bacteria } & Pseudomonas tolaasii & 2,192 & - & Mushroom \\
\hline & Pseudomonas syringae pv tabaci & ICMP 2706 & - & Tobacco \\
\hline & Pseudomonas syringae pv panici & ICMP 3955 & - & Rice \\
\hline & Pseudomonas caryophylli & NCPPB349 & Italy & Carnations \\
\hline & Pseudomonas syringae pv syringae & B475 & - & Mango \\
\hline & Pseudomonas syringae pv japonica & ICMP 6305 & - & Wheat \\
\hline & Pseudomonas syringae pv papulans & Psp26 & - & Apple \\
\hline
\end{tabular}

strains grown overnight in TY broth were placed on the opposite four sides of the plates $1.5 \mathrm{~cm}$ away from the fungal disc. This method was repeated for each fungus. Controls consisted of plates containing the fungal plugs alone. All plates were incubated at $28^{\circ} \mathrm{C}$ for $5-7$ days. The antagonism activity against bacterial phytopathogens was performed as described in Li et al. (2020) with some modifications. Bacterial pathogens were streaked on TY plates and incubated at $25^{\circ} \mathrm{C}$ overnight. Single colonies were suspended in TY broth and incubated at $25^{\circ} \mathrm{C}$. Approximately $1 \times 10^{-6} \mathrm{CFU} / \mathrm{ml}$ were mixed with melted $0.8 \%$ TY agar medium before pouring plates. After solidification, $5 \mu \mathrm{l}$ of bacterial isolates solution $\left(\mathrm{OD}_{600}=1.0\right)$ was spot inoculated onto the plates and incubated at $28^{\circ} \mathrm{C}$ for $48 \mathrm{~h}$, before measuring the diameters of inhibition halos. All experiments were performed in triplicate.

\section{Identification of Biosynthetic Gene Clusters}

Obtained genomes were analyzed by antiSMASH 5.0 (Blin et al., 2019) and BAGEL 4 (van Heel et al., 2018) to identify biosynthetic gene clusters (BCGs) of potential antimicrobial compounds such as non-ribosomal peptide synthetases (NRPSs), polyketide synthases (PKSs), post-translationally modified peptides (RiPPs), hybrid lipopeptides (NRPS-PKS) and bacteriocins. Biosynthetic Gene Clusters that shared less than $70 \%$ amino acid identity against known clusters were regarded as novel.

\section{RESULTS AND DISCUSSION}

\section{Isolation and Characterization of Spore- Forming Plant-Growth-Promoting Bacteria} Spore-forming bacteria were specifically isolated from sand samples collected from gaps among nurse plants, belonging to the genus J. sabina, in salt-pans as described in the Materials and Methods section. Based on morphological characteristics, a total of 20 isolates were selected and preliminarily characterized for growth properties (Supplementary Table S2). All the strains can be classified as facultative anaerobic, mesophiles and moderate halophiles, excluding RHF5 strain, which survives up to $60^{\circ} \mathrm{C}$ and strain RHFB unable to grow at temperature and salt concentration higher than $37^{\circ} \mathrm{C}$ and $5 \% \mathrm{NaCl}$, respectively (Ventosa et al., 1998; Schiraldi and De Rosa, 2016).

To identify potential PGPB, the 20 strains were evaluated in vitro for physiological traits associated with plant growth enhancement and biocontrol ability (Table 2). Strain performance was compared with those of two promising PGPB, RHFS10, and RHFS18 strains, belonging to the Bacillus genus and isolated from J. sabina rhizosphere of the same collection site (Castaldi et al., 2021) and proposed as biocontrol agents for their antagonistic activity against the phytopathogen $M$. phaseolina. Most of the new strains displayed root-colonization phenotypes since able to surface spread by swarming and to form biofilms (Amaya-Gómez et al., 2020), while only five were found either positive to both solubilization of phosphate, indoleacetic acid (IAA), and siderophore production. Strains RHF6, RHF15, and RHFB showed a better performance than when compared against the already characterized rhizobacteria strains RHFS10 and RHFS18, confirming that the microenvironments created under or nearby nurse shrubs are a promising source of PGPB (Rodríguez-Echeverría et al., 2016). All bacterial isolates were tested for in vitro activities of their extracellular hydrolytic enzymes (lipase, protease, amylase, xylanase, and cellulase) usually associated with biocontrol activity ( $\mathrm{Pal}$ and McSpadden Gardener, 2006). As reported in Table 2, the highest hydrolytic activity was observed for RHF12, RHF15, and RHFB strains, comparable with that exerted by rhizosphere strains RHFS10 and RHFS18.

Based on these results reported in Table 2, seven strains were selected for whole-genome sequencing analysis. All selected strains were able to solubilize phosphate with efficiency higher than the other ones and to produce Biofilm, IAA, and siderophores. Further, strains RHF12, RHF15, RHFB, and RHFS18 emerged for their strong hydrolytic potential, often associated to biocontrol activity (Castaldi et al., 2021), while strain RHF6 showed the ability to growth up to $13 \% \mathrm{NaCl}$, showing the best salt tolerance (Supplementary Table S2).

\section{Genome Sequencing and Phylogenetic Analysis}

The obtained genomes had coverage of $\sim 30 \times$, with a variable number of contigs between 40 and 1,105 for RHF15 and 
TABLE 2 | Summary of plant growth-promoting and biocontrol traits exhibited by 20 spore-forming bacteria isolates.

\begin{tabular}{|c|c|c|c|c|c|c|c|c|c|c|}
\hline \multirow{2}{*}{ Strain } & \multicolumn{5}{|c|}{ PGPB activities } & \multicolumn{5}{|c|}{ Hydrolytic activities } \\
\hline & Biofilm $\left(O D_{570}\right)$ & Swarming & PVK & IAA ( $\mu \mathrm{g} / \mathrm{ml})$ & Siderophores & Lipase & Protease & Amylase & Xylanase & CMC \\
\hline $\mathrm{RHF1}$ & - & ++ & ++ & - & + & - & ++ & ++ & + & ++ \\
\hline RHF2 & 0.2 & + & + & 18 & + & - & + & + & + & + \\
\hline RHF3 & - & - & - & - & - & + & ++ & ++ & + & - \\
\hline $\mathrm{RHF} 4$ & - & + & - & - & + & + & ++ & ++ & - & + \\
\hline RHF5 & 0.2 & - & - & 2 & - & - & + & ++ & - & - \\
\hline RHF6 & 0.3 & + & ++ & 31 & ++ & - & + & + & + & ++ \\
\hline $\mathrm{RHF7}$ & 0.4 & - & - & - & - & - & + & + & - & - \\
\hline RHF8 & 0.6 & ++ & - & 6 & - & - & ++ & ++ & ++ & - \\
\hline RHF9 & - & - & + & 3.2 & - & - & ++ & ++ & - & - \\
\hline RHF10 & - & - & - & 4 & - & - & ++ & + & + & + \\
\hline RHF11 & 0.2 & + & - & - & - & - & + & + & + & - \\
\hline RHF12 & 0.7 & ++ & + & 25 & ++ & - & ++ & ++ & ++ & ++ \\
\hline RHF13 & - & ++ & ++ & 3 & + & + & - & ++ & + & ++ \\
\hline RHF14 & - & - & - & - & - & + & + & + & + & - \\
\hline RHF15 & 0.6 & ++ & ++ & 23 & ++ & + & ++ & ++ & ++ & ++ \\
\hline RHF16 & - & - & - & - & - & + & + & + & - & - \\
\hline RHF17 & 0.5 & ++ & + & - & + & + & + & + & ++ & + \\
\hline RHFB & 0.3 & + & ++ & 32 & ++ & ++ & ++ & ++ & ++ & + \\
\hline RHFE & - & - & - & - & - & + & + & + & - & - \\
\hline RHFL & 0.3 & - & - & - & - & - & + & + & - & - \\
\hline${\text { RHFS } 10^{1}}^{1}$ & 0.3 & ++ & + & 12 & ++ & ++ & ++ & ++ & ++ & ++ \\
\hline RHFS18 $^{1}$ & 0.5 & + & + & 12 & ++ & + & ++ & ++ & ++ & ++ \\
\hline
\end{tabular}

No activity (-), halo or colony diameter $<5 \mathrm{~mm}(+)$, halo or colony diameter $\geq 5 \mathrm{~mm}(++)$, halo or colony diameter $10 \mathrm{~mm}(+++)$. Data are represented by means of at least three replicates \pm SE at $p \leq 0.05$ using LDS. The strains selected for further studies are indicated in bold. PVK, Pikovskaya; IAA, indoleacetic acid; and CMC, carboxymethylcellulose. ${ }^{1}$ Available from Castaldi et al. (2021).

TABLE 3 | General features of the assembled genomes.

\begin{tabular}{|c|c|c|c|c|c|c|c|}
\hline \multirow{2}{*}{ Analysis statistics } & \multicolumn{7}{|c|}{ Strains } \\
\hline & RHFB & RHF2 & RHF6 & RHF12 & RHF15 & RHFS10 & RHFS18 \\
\hline Size (bp) & $5,648,757$ & $4,003,762$ & $4,066,378$ & 4,096,200 & 4,232,838 & $4,254,653$ & $3,936,406$ \\
\hline Number of contigs & 158 & 52 & 156 & 280 & 40 & 46 & 1,105 \\
\hline Mean GC content (\%) & 40.57 & 43.74 & 46.3 & 44.01 & 43.39 & 43.95 & 46.14 \\
\hline CDS & 5,413 & 3,988 & 3,901 & 3,997 & 4,282 & 4,182 & 3,87 \\
\hline N50 & 187,761 & 413,219 & 584,325 & 60,229 & $2,184,724$ & $1,139,270$ & 6,179 \\
\hline N75 & 82,022 & 306,766 & 292,476 & 34,071 & $1,049,735$ & 348,257 & 3,118 \\
\hline L50 & 11 & 3 & 2 & 19 & 1 & 2 & 176 \\
\hline L75 & 21 & 6 & 4 & 42 & 2 & 4 & 397 \\
\hline
\end{tabular}

RHFS18, respectively (Table 3 ). The genome of strain RHFS18 was particularly fragmented, and repeated sequencing of the same strain did not yield improved assembly suggesting that the results are not dependent on a low-quality sequencing library. The obtained genomes are approximately $4.0 \mathrm{Mbp}$ long except for RHFB's genome, being the longest $(5.6 \mathrm{Mbp})$ and the one with the highest number of predicted protein coding sequences compared to the others. Taxonomic identification of the strains was based on the phylogenetic analysis of the $16 \mathrm{~S}$ rRNA sequence as well as the whole genome Average Nucleotide Identity. All the isolates were identified as members of the genus Bacillus (Figure 1) with six strains out of seven clustering into the same clade, and only strain RHFB falling in a different clade. The phylogenetic divergence observed for RHFB from the other strains agrees with the observed differences in physiological traits for this strain (Supplementary Table S3). Since most Bacillus species are phylogenetically close, 16S rRNA analysis is not always exhaustive to obtain an unambiguous assignment (Rooney et al., 2009). To overcome this issue and classify the strains at the species level, whole genome ANI was used (Table 4). Strain RHFB exhibited 96.95\% ANI against the genome of the closest relative Brevibacterium frigoritolerans and was therefore identified as a B. frigoritolerans species. Strain RHF2 was identified as Bacillus subtilis, based on 99.96\% ANI score. Strains RHF6 and RHFS18 were classified as members of the Bacillus amyloliquefaciens species, exhibiting 99.26 and 98.36\% ANI, respectively. Strain RHF12 was identified as Bacillus halotolerans, based on $98.04 \%$ ANI score, while RHF15 was classified as Bacillus gibsonii, showing 99.6\% ANI score. As shown in Table 4, RHFB, RHF12, and RHFS18 strains were 


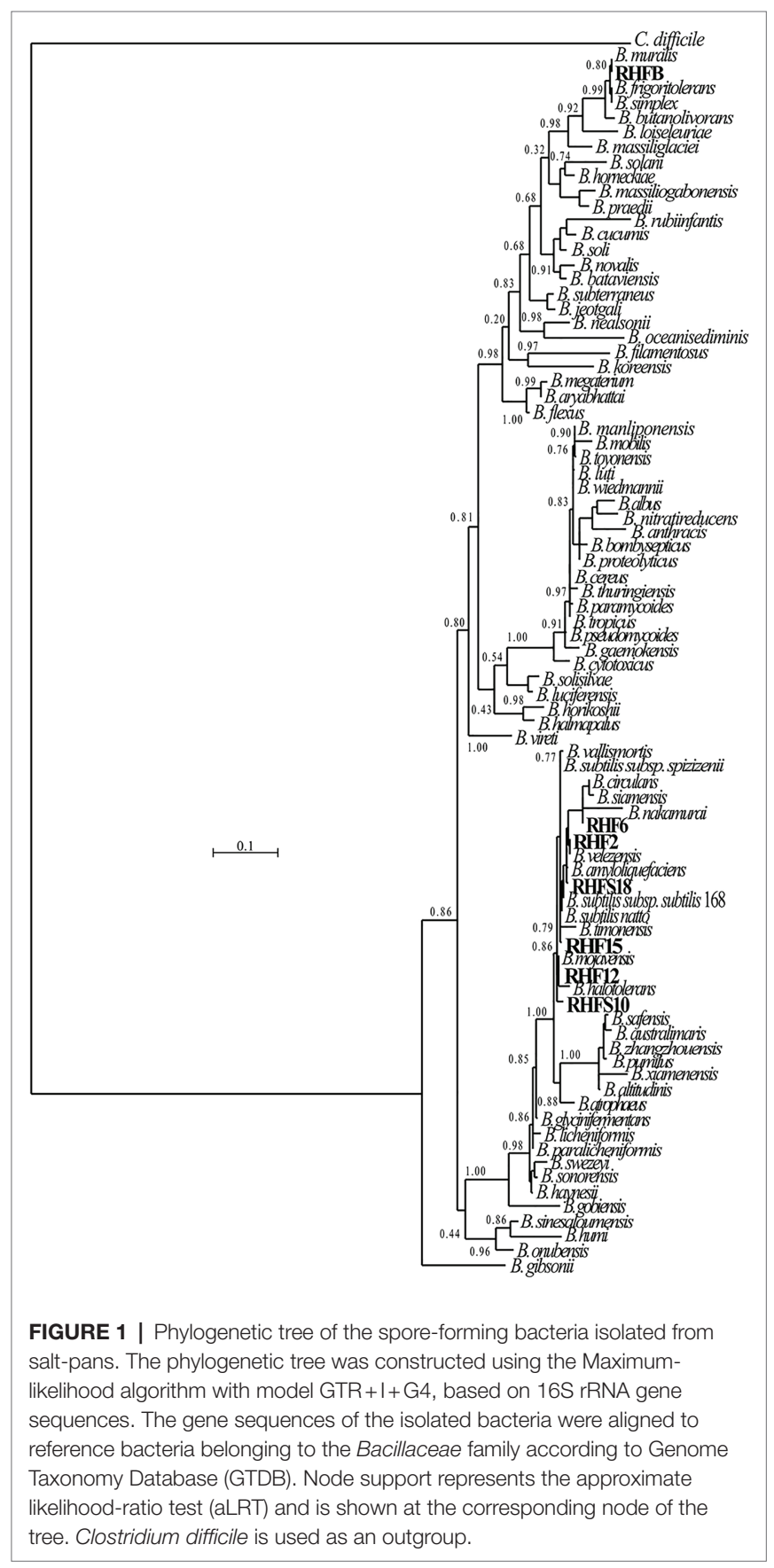

univocally matched with the same species, while for RHF2, RHF6, and RHF15 strains the two analyses returned different results. This mismatch between the two methods of classification is due to the poor discrimination between closely related species of the Bacillus genus due to their high morphological, biochemical, and genetic similarities (Celandroni et al., 2019). Since taxonomy annotations based on genetic markers, such as the 16S rRNA gene, can give variable results depending on the strain, ANI-based classification has been preferred in this study when showing ANI scores $\geq 95 \%$ (Jain et al., 2018). Based on this, RHF2, RHF6, and RHF15 were identified as
TABLE 4 | Classification of the seven selected strains.

\begin{tabular}{lll}
\hline & 16S rRNA similarity & ANI (best score) \\
\hline RHFB & B. frigoritolerans (100\%) & B. frigoritolerans $(96.95 \%)$ \\
RHF2 & B. velezensis $(99.87 \%)$ & B. subtilis $168(99.96 \%)$ \\
RHF6 & B. velezensis (100\%) & B. amyloliquefaciens (99.26\%) \\
RHF12 & B. halotolerans (98.51\%) & B. halotolerans $(98.04 \%)$ \\
RHF15 & B. subtilis (100\%) & B. gibsonii (99.6\%) \\
RHFS10 & B. halotolerans (97.5\%) & B. vallismortis $(93.48 \%)$ \\
RHFS18 & B. amyloliquefaciens (100\%) & B. amyloliquefaciens (98.36\%)
\end{tabular}

The 16S rRNA similarity and ANI score against the closest relative identified from the phylogenetic analysis are reported for each isolate.

B. subtilis, B. amyloliquefaciens, and B. gibsonii, respectively (Table 4). Only strain RHFS10 could not be classified at the species level due to the low ANI score (93.48\%) when compared with the closest relative Bacillus vallismortis and it was classified as Bacillus sp. RHFS10 (Table 3). Further analysis will be required to fill this classification gap.

\section{Environmental Adaptation to Halophilic Conditions}

The phenotypic plasticity of the salt-pans isolates was investigated by comparing their growth parameters against the closest Bacillus species identified by the ANI analysis (Table 4). Temperature, $\mathrm{pH}$, and salinity ranges required for growth were evaluated. These parameters are useful to identify distinct phenotypic strategies used by microorganisms to better adapt to environmental conditions (Agrawal, 2001). As expected, taxonomically closer strains showed small differences when compared with each other or with their representative species (red dashed lines in Figure 2). As already highlighted by the phylogenetic analysis, B. frigoritolerans RHFB strain presented a diverging phenotype, especially considering the lower salt tolerance compared to the other isolates. Interestingly, some strains, like $B$. halotolerans RHF12, B. gibsonii RHF15, and Bacillus sp. RHFS10, showed identical growth properties even though belonging to three different Bacillus species (Figure 2), while strains of the same species, like B. amyloliquefaciens RHF6 and RHFS18, exhibited different adaptations to $\mathrm{NaCl}$ concentration and $\mathrm{pH}$ range. Moreover, B. amyloliquefaciens RHF6 like B. subtilis RHF2 were able to grow at higher salt concentrations than their representative species, suggesting an adaptive phenotypic variation to the high salinity condition of salt-pans.

\section{Analysis of Potential PGP and Biocontrol Traits}

To confirm the in vitro PGP characterization of the isolates, a prediction of the genes (Figure 3 ) and proteins (Table 5) involved in biocontrol activity and plant growth promotion was performed. The analyses identified genes that can be attributed to the strains ability to improve nutrient availability, suppress pathogenic fungi, and resist oxidative stress and quorum sensing in all analyzed genomes. For instance, the genome of most of the seven strains included the pyrroloquinolone quinone synthase (pqq) and the dependent glucose dehydrogenase $(g d h)$ 


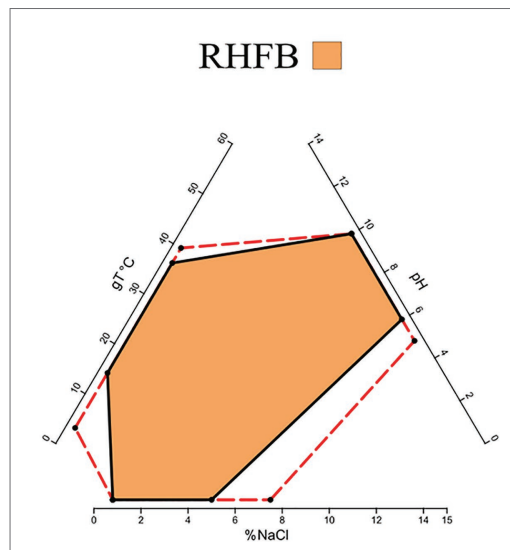

B. frigoritolerans

RHF12

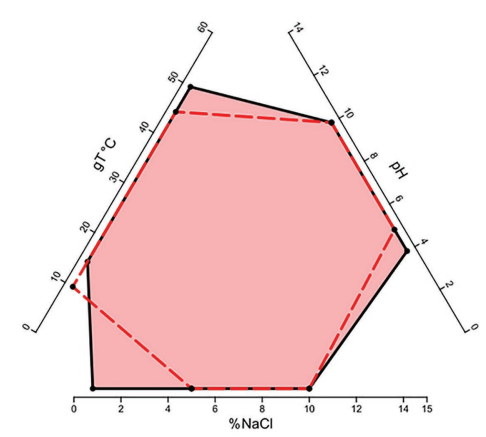

B. halotolerans

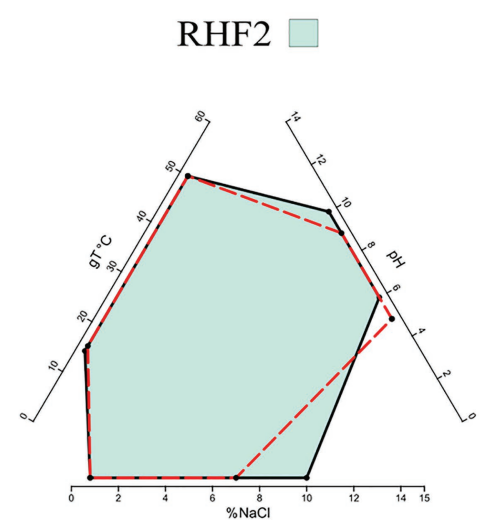

B. subtilis RHF15

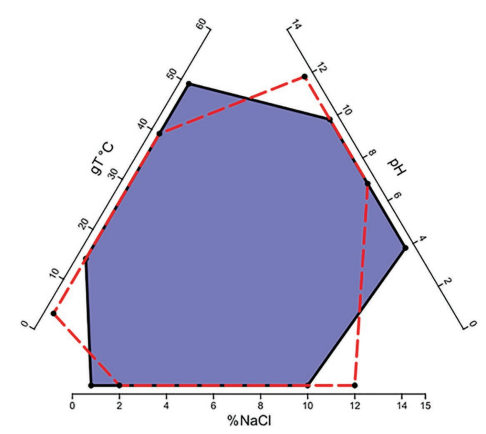

B. gibsonii

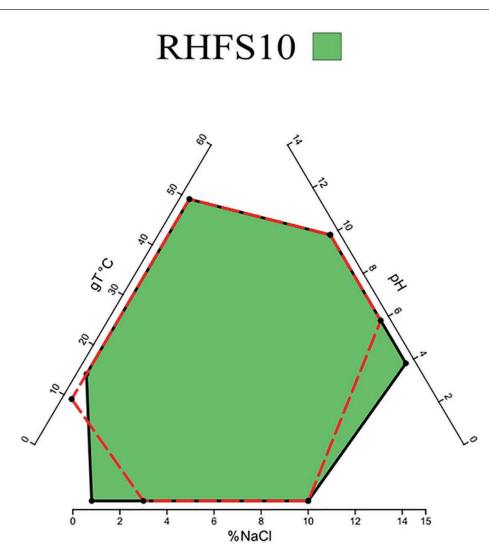

B. vallismortis

FIGURE 2 | Phenotypic plasticity of the salt-pan isolates. Multivariate polygons plots (Giovannelli et al., 2021, in preparation) showing the growth temperature $\left(\mathrm{gT}^{\circ} \mathrm{C}\right), \mathrm{pH}$, and salinity (\% NaCl) boundaries observed for the seven isolates (polygons) and the range for the closest relative identified by ANI (red dashed lines). Each edge represents the range for the specific variables projected onto the axis. More information about polygons plot can be found at https://giovannellilab. github.io/polygonsplot/.

genes, involved in mineral phosphate solubilization as well as antifungal activities and systemic resistance induction. Interestingly, both isolates B. amyloliquefaciens RHF6 and RHFS18 did not carry the cofactor pqq gene cluster, suggesting that other mechanisms could co-exist (Table 2). IAA is one of the most common and effective plant-growth hormones. Besides plants, most rhizobacteria can produce and secrete IAA, increasing the growth and the yield of crops (Bunsangiam et al., 2019). All the strains produced Tryptophan-2monooxygenase and Indole-3-acetamide hydrolase, able to convert Tryptophan in Indole-3-acetamide and then in IAA, respectively (Bunsangiam et al., 2019). The presence of other tryptophan synthases orthologs (subunits a and b) in all the analyzed genomes suggests alternative IAA biosynthesis pathways potentially involving different intermediates. This hypothesis is supported by the observation that $B$. frigoritolerans RHFB, one of the best IAA producers among the isolated PGPB, possessed the indole-3-pyruvate decarboxylase, a key enzyme of another Trp-dependent pathway for IAA production (Sitbon et al, 2000).

All the strains were predicted to be potentially able to fix nitrogen and produce nitric oxide, both useful features in agricultural practices (Ahmad et al., 2013), and to synthesize polyamines, as spermidine and putrescine, and the ACC deaminase, involved in lateral root development and plant growth enhancement under abiotic stress (Xie et al., 2014; Gupta and Pandey, 2019).

As expected, the genome of all the halophilic Bacillus strains contained multiple genes involved in antioxidant response, such as peroxidases, catalases, superoxide dismutase, and glutathione peroxidase (Hassan et al., 2020; Figure 3; Table 5). Other enzymes involved in abiotic stress responses were identified in the strains, as the osmoprotectants choline dehydrogenase, betaine-aldehyde dehydrogenase, and proline dehydrogenase (Table 5). The predicted production of osmotically active metabolites, as well as ROS scavenging enzymes, reflects the 

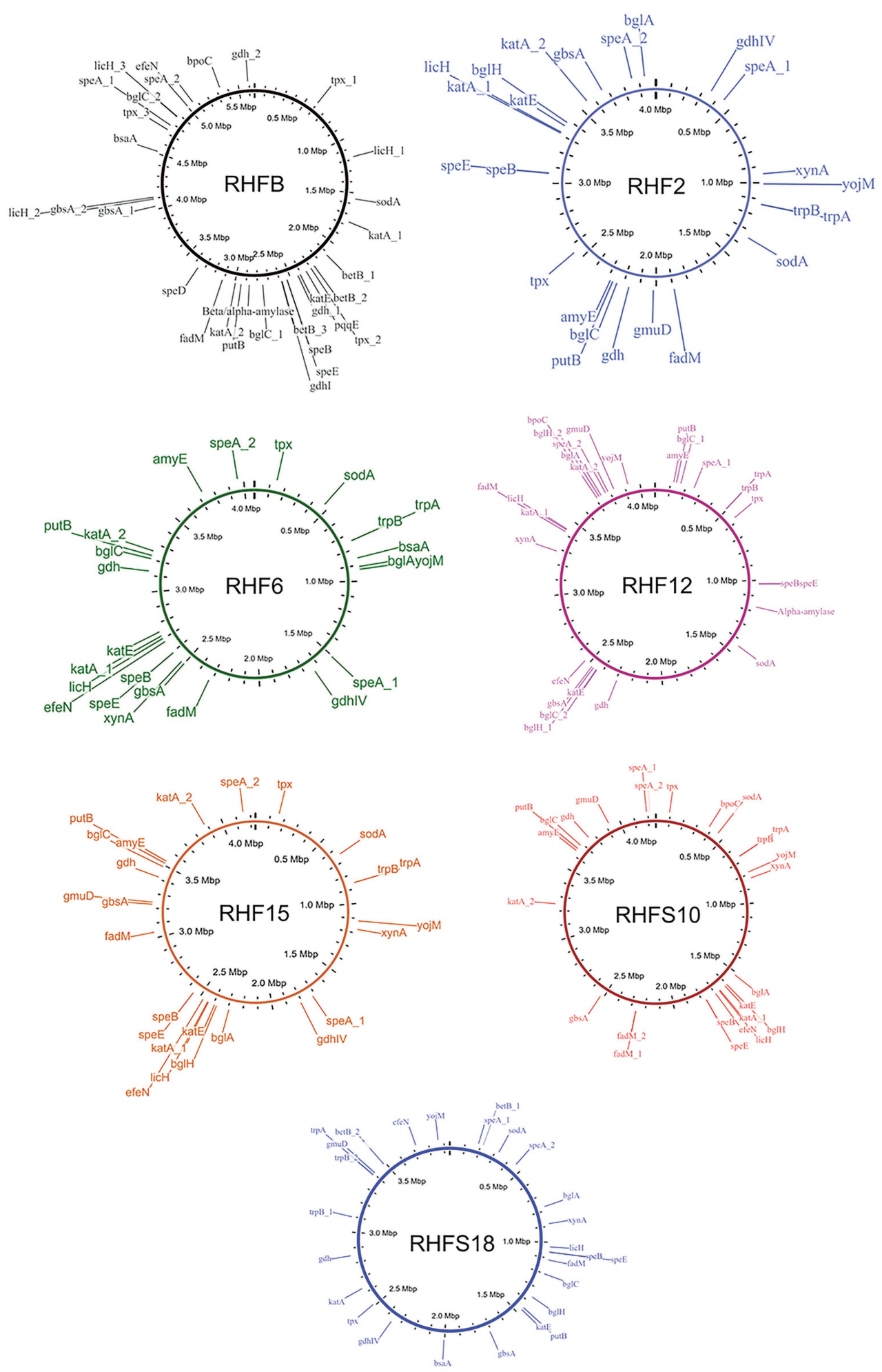

FIGURE 3 | Whole genome representations of the seven isolates showing the location of the identified PGP trait genes.

ability of the selected strains to survive in extreme environments, as salt-pans and to potentially alleviate abiotic stress in agricultural system.
Finally, all the isolates possessed in their genomes genes encoding for hydrolases involved in fungal cell-wall and starch degrading pathways, confirming the results obtained with the 
TABLE 5 | Plant-Growth-Promoting traits-associated proteins identified in the proteome of the selected strains and their abundance.

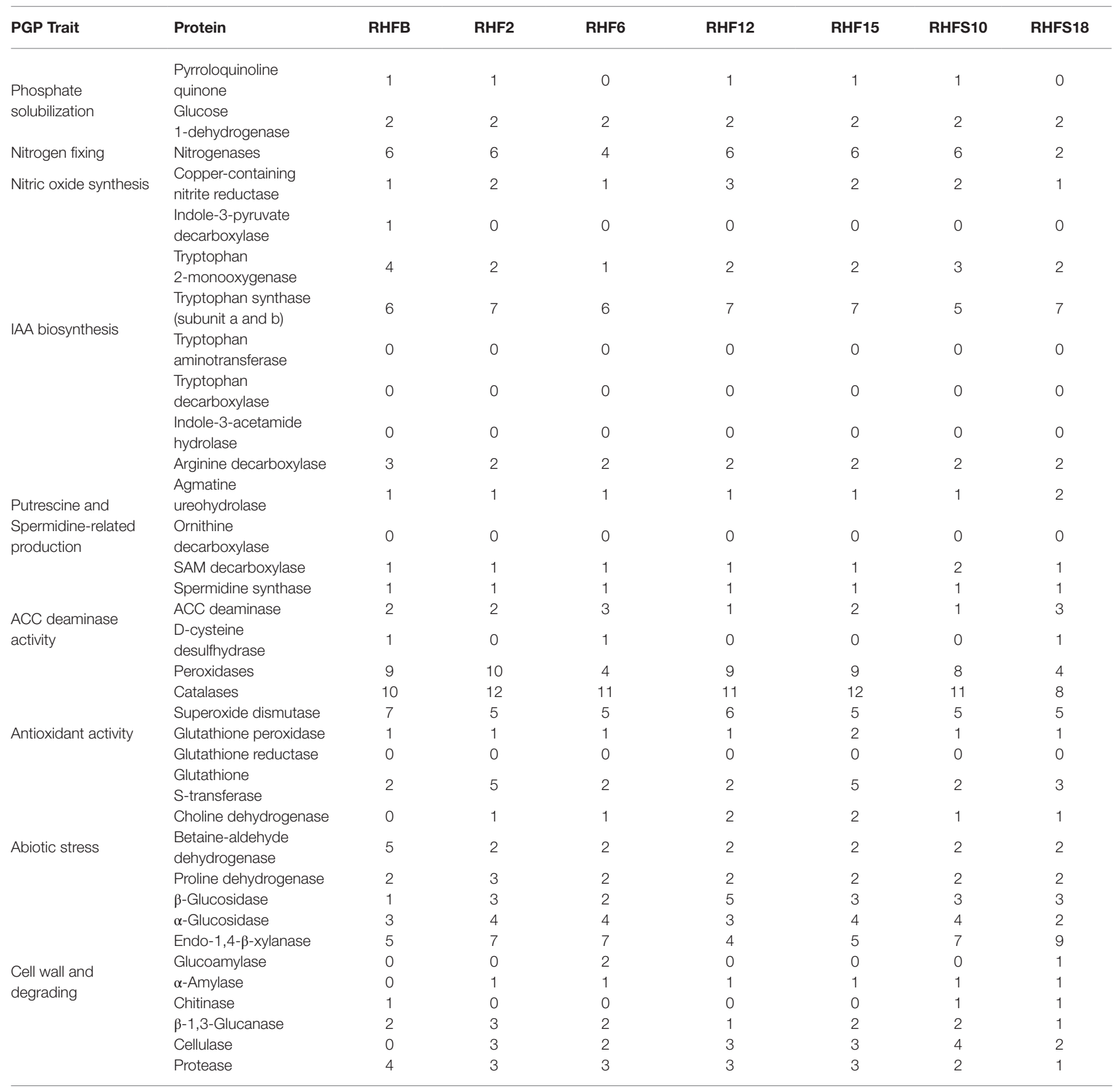

Only $\geq 40 \%$ similarity scores were considered. IAA, indole-3-acetic acid; ACC, 1-aminocyclopropane-1-carboxylate.

in vitro analysis, except for strain $B$. frigoritolerans RHFB whose genome did not carry $\alpha$-amylase or cellulase genes.

\section{Antimicrobial Activity Screening}

To verify the antagonistic potential that emerged from the genome-mining, the isolates were dually cultured with fungal and bacterial plant pathogens (see Table 1 for a list of the used phytopathogens). The results reveal that isolates inhibited plant pathogens growth on plates with different efficiency (Figure 4). Strains B. subtilis RHF2, B. amyloliquefaciens RHF6, and Bacillus sp.
RHFS10 showed a broad inhibitory spectrum, being able to antagonize both phytopathogenic fungi and bacteria, while $B$. halotolerans RHF12 and B. amyloliquefaciens RHFS18 exhibited an antimicrobial activity limited to fungi. The highest antagonistic activity was observed for strain Bacillus sp. RHFS10, capable of inhibiting the growth of most of the test pathogens, confirming its biocontrol potential already observed by Castaldi et al. (2021). Unexpectedly, $B$. frigoritolerans RHFB exhibited no activity at all. Nevertheless, in the last decade, this species has been identified as a potential insect pathogenic bacterial species, with nematicidal 


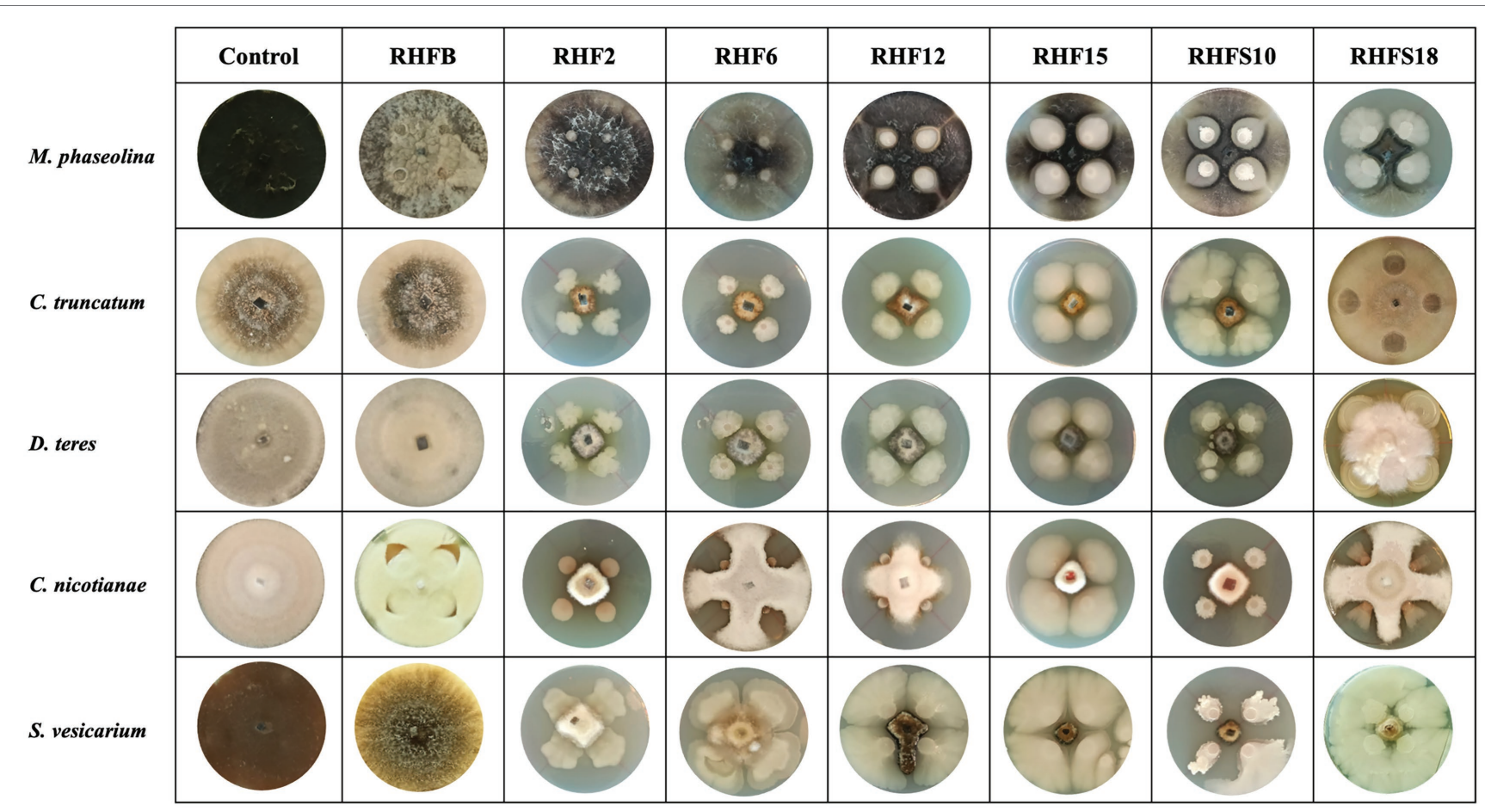

FIGURE 4 | Representative photographs of dual culture assay for in vitro mycelial growth inhibition of fungal phytopathogens.

activity (Selvakumar et al., 2011). The diversity observed in the antimicrobial activity against plant pathogens highlighted the phenotypic diversity of sand and rhizosphere isolated Bacilli, suggesting that in nature plant-associated bacteria may encounter different phytopathogens that may induce the acquisition of different antagonistic activity.

\section{Genome Mining for Biosynthetic Gene Clusters}

The biocontrol potential and the ability to enhance plant growth of PGPB are mostly attributed to their bioactive secondary metabolites. Proteins and metabolites released in the soil by PGPB, indeed, are implicated in root colonization, as well as in interactions with the plant immune response and the surrounding niche (Lugtenberg and Kamilova, 2009; Pieterse et al., 2014; Jamali et al., 2020). The strong antimicrobial activity of selected Bacillus strains is most likely due in part to the production of hydrolytic enzymes and siderophores observed in in vitro assays and confirmed by genome analysis (Tables 2 and 5). To better investigate this antagonistic activity, the biosynthetic potential of the halophilic PGPB was evaluated by using antiSMASH 6.0 .0 to predict both characterized and unknown functioned secondary metabolites (Figure 5).

The bacterial isolates harbored BGCs coding for NRPSs, polyketide synthases (PKSs), post-translationally modified peptides (RiPPs), hybrid lipopeptides (NRPS-PKS; Figure 5A), and the majority of the BGCs are assigned to known products (Figure 5B; Supplementary Table S4). The unknown BGCs are type 3 polyketide synthase (T3PKS), RiPPs and terpenes (Figure 5C; Supplementary Table S4).

\section{Novel Non-ribosomal Peptide Synthetases and Bacteriocins}

NRPs are modular enzymes that synthesize secondary metabolites, some of which are known to be involved in plant disease control (Ongena and Jacques, 2008). Several bioactive compounds produced by Bacillus strains fit in this category, such as surfactin or fengycin (Keswani et al., 2020), both of them exhibiting antimicrobial activity potentially exploited for biocontrol in agriculture. We have identified one novel BGC belonging to the class of the NRPs from $B$. amyloliquefaciens RHF6 (Figure 6). This cluster of $66.3 \mathrm{~Kb}$ has six genes encoding 25 domains, which include six condensation (C) domains, seven adenylation (A) domains, one coenzyme A ligase (CAL) domain, two epimerization (E) domains, one thioesterase (TE) domain, one heterocyclization (Cy) domain and seven peptidyl carrier protein (PCP) domains. Among them, 24 domains are essential components of this cluster, and catalyze the incorporation of seven amino acids into the final product exhibiting the following sequence: D-Cys-Ser-Cys-Ala-Asn-D-Asn. This cluster shows no similarity to any known BGCs reported in the antiSMASH database (Supplementary Table S4). The single heterocyclization $(\mathrm{C})$ domain in the first module of the BGC, could form a thiazoline ring from a residue of cystine (Cys). Interestingly, many antimicrobial drugs expose a thiazoline ring (Desai et al., 2016). This allows us to speculate on the potential antimicrobial activity of the compound produced by this novel BGC.

The seven genomes were also mined for potential novel bacteriocins BGCs using BAGEL4. Bacteriocins are ribosomally 


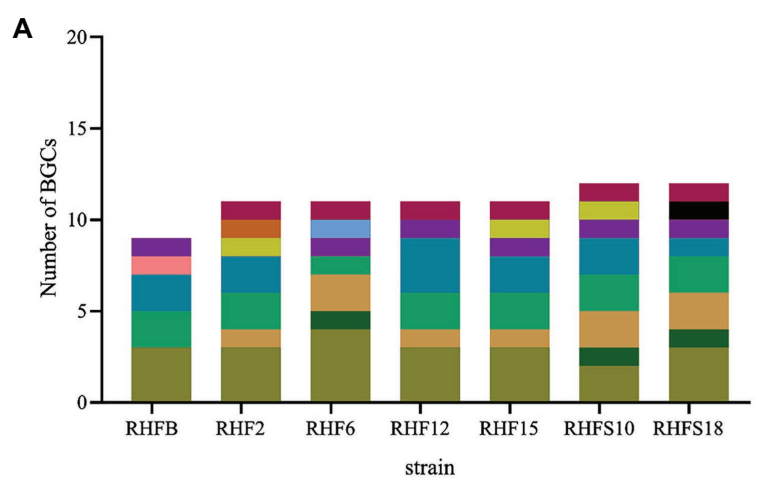

C

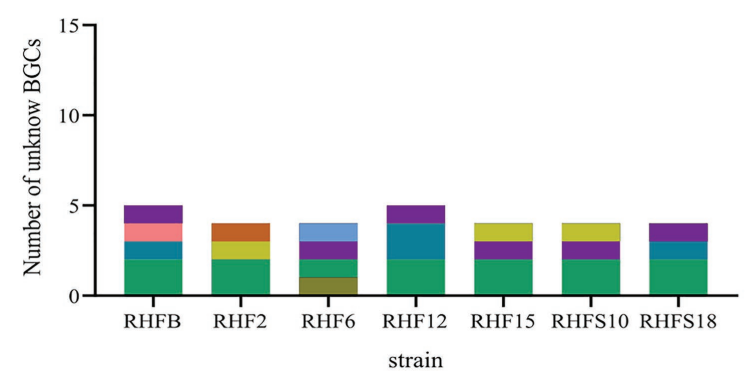

B

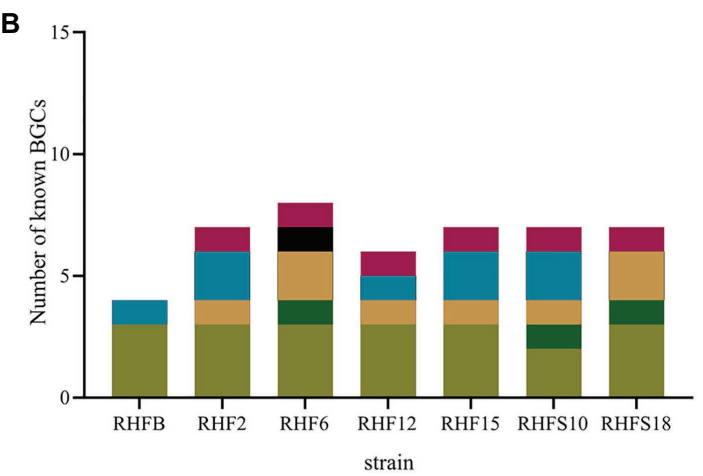

D

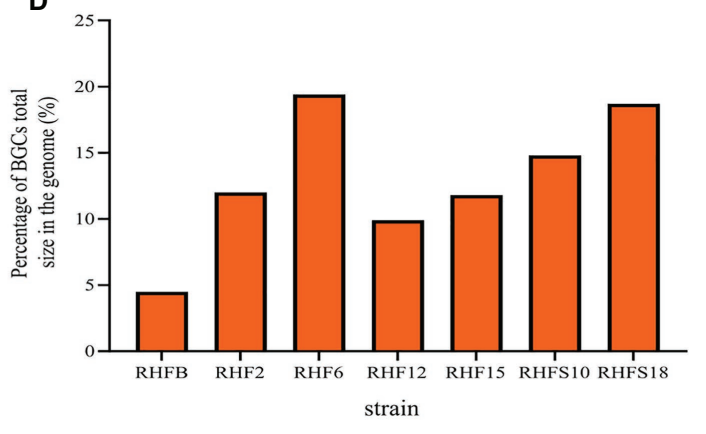

FIGURE 5 | Number of biosynthetic gene clusters harbored by the strains and the percentage contribution of Biosynthetic Gene Clusters (BGCs) to the total genome size. (A) Total number of BGCs; (B) number of reported BGCs in the genomes; (C) number of unknown BGCs. BGCs that have different numbers of genes or show less than $70 \%$ protein identity to the reported ones were regarded as novel; and (D) the percentage contribution of BGCs to the genomes.

\section{B. amyloliquefaciens RHF6 (Cluster 7) BGC NRPs 66315 bp}

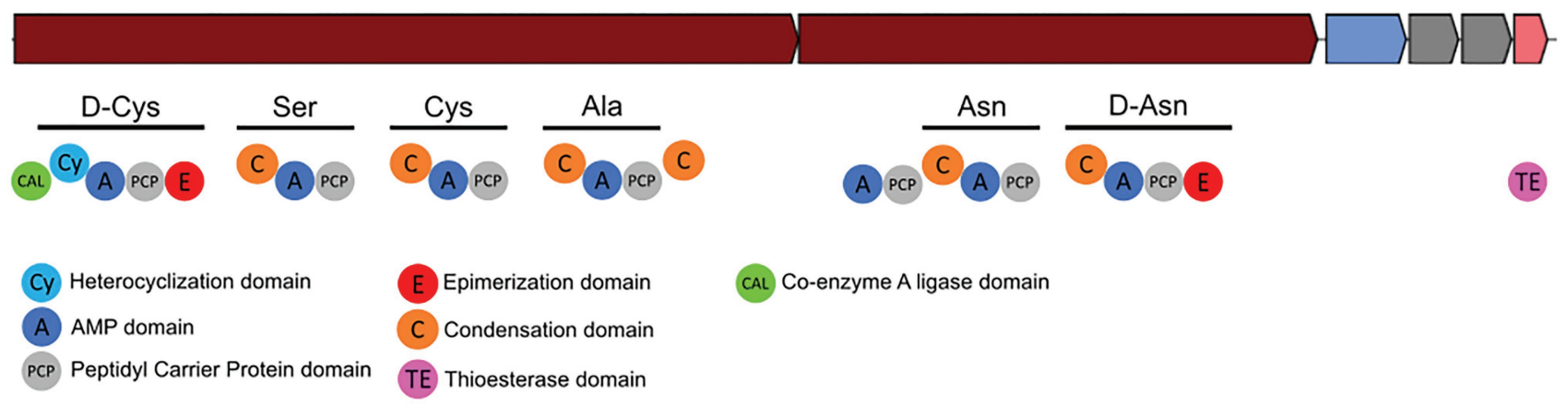

FIGURE 6 | Novel NRP Biosynthetic gene Clusters identified from the isolate Bacillus amyloliquefaciens RHF6.

synthesized antimicrobial peptides, generally active against bacteria closely related to producers (Cotter et al., 2013), and classified into three main classes: class I comprehends ribosomally produced and post-translationally modified peptides (RiPPs); class II unmodified peptides, and class III large antimicrobial peptides (Zhao and Kuipers, 2016). These molecules are directed against competitive microorganisms, and therefore generate a selective advantage for the producers. Generally, bacteriocins are highly specific against their target, although some might have a wider spectrum
(Jack et al., 1995). The analysis made using BAGEL4, returned 15 regions of interest (in contrast with the antiSMASH analysis which revealed a higher number of bacteriocins, Supplementary Table S4), even though only six of them could be classified as novel bacteriocins, sharing $\leq 70 \%$ of similarity with known sequences from BAGEL4 database (Figure 7).

One orphan BGC of 27 genes is carried by both $B$. amyloliquefaciens RHF6 and RHFS18 strains (Figures 7a.1,d.1), although the core biosynthetic genes encode two different 
A B. amyloliquefaciens

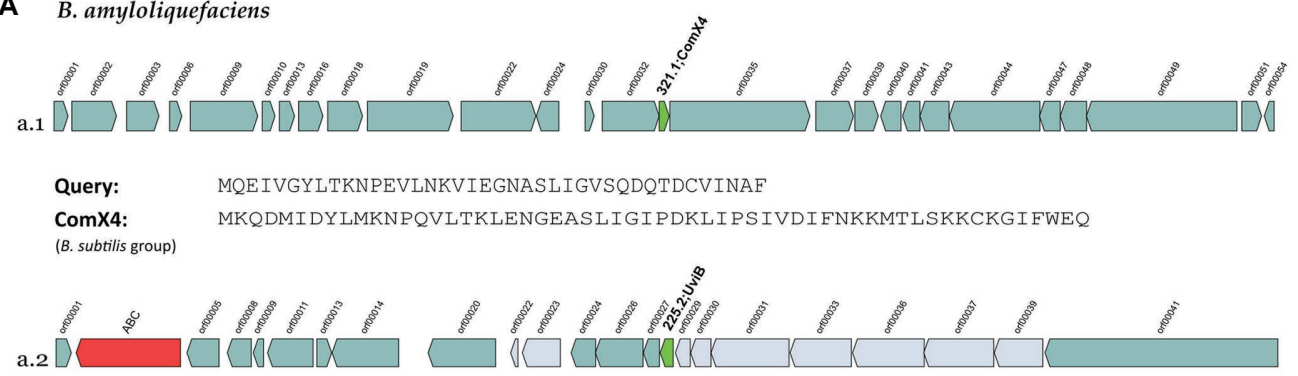

Query: $\quad$ MEMDIMQYLMTQGPFAVLFCSLIYYVMKTSREREAKLYGQIDSQNELLARFSDKYEIVIDKLD

UviB: MDSELFKLMATQGAFAILFSYLLFYVLKENSKREDKYQNI IEELTELLPKIKEDVEDIKEKLNK

B

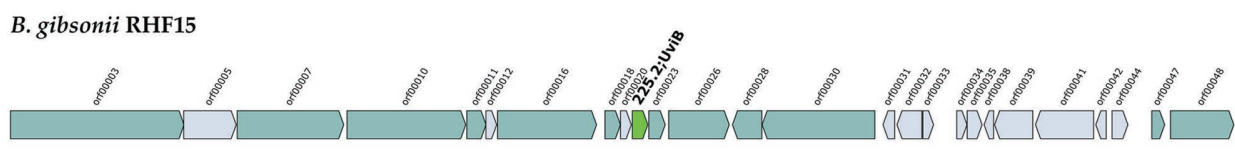

Query: VFLFCHEGGEGFMEMDITQYLITQGPFAVLFCWLLFYVMKTSKEREAKLYNQIDSQNEVLGKFSEKYDVVIEKLDK

UviB: $\quad$ MKKAVIVENKGCATCSIGAACLVDGPIPDFEIAGATGLFGLWG

(C. perfringens)

C $\quad$ B. spp RHFS10

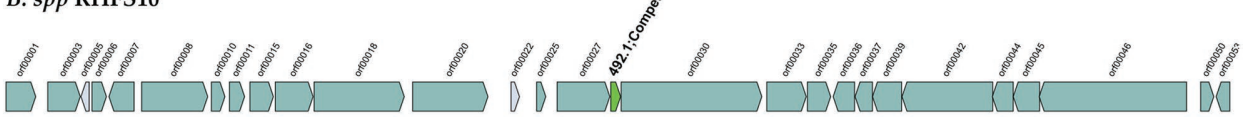

Query:

MQEMVGYLIKY PNVLREVMEGNACLLGVDKDQSECI INGE

Competence: MQDLINYFLNYPEALKKLKNKEACLIGEDVQETETI IKAYNDYYLADPITRQWGD

(B. subtilis strain 168)

D

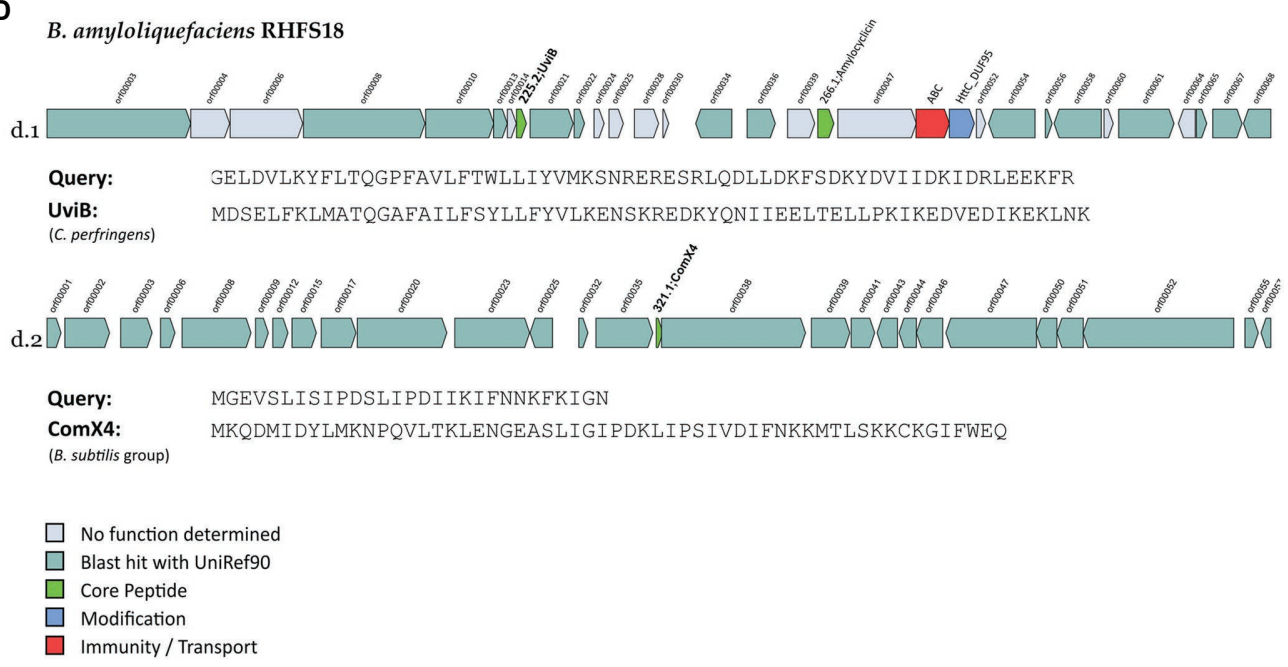

FIGURE 7 | Novel bacteriocins identified from the isolated Bacillus strains (A: B. amyloliquefaciens, B: B. gibsonii RHF15, C: B. spp. RHFS10 and, D: B. amyloliquefaciens RHFS18). The BGCs identified from BAGEL4 analysis are shown and compared to the most similar available in BAGEL4 database.

precursor peptides of 40 and 29 amino acids, respectively, sharing 41.03 and $57.14 \%$ of similarity with ComX4 from the B. subtilis group. In particular, ComX4 belongs to the ComX subclass of RiPPs according to the BAGEL4 database, and it is part of a major quorum-sensing system that regulates the development of genetic competence (Okada et al., 2005) and the production of surfactins (Caulier et al., 2019). Bacillus amyloliquefaciens RHF6 also harbors a BGC of 23 genes (Figure 7A-a.2), with the core biosynthetic gene encoding a 63-amino acids precursor peptide, showing a similarity of $36.51 \%$ compared to UviB, a class II bacteriocin first identified in the mobilizable plasmid pIP404, from C. perfringens, known to be bacteriocinogenic (Garnier and Cole, 1988). Interestingly, two different BGCs containing the same gene encoding for a 
TABLE 6 | Antimicrobial activity of the seven selected strains against phytopathogenic fungi and bacteria.

\begin{tabular}{|c|c|c|c|c|c|c|c|c|}
\hline Pathogen types & Species & RHFB & RHF2 & RHF6 & RHF12 & RHF15 & RHFS10 & RHFS18 \\
\hline \multirow[t]{5}{*}{ Fungi } & M. phaseolina & - & - & - & + & ++ & +++ & +++ \\
\hline & C. truncatum & - & - & +++ & +++ & +++ & +++ & +++ \\
\hline & D. teres & - & - & +++ & +++ & +++ & +++ & +++ \\
\hline & C. nicotianae & - & +++ & ++ & ++ & +++ & +++ & ++ \\
\hline & S. vesicarium & - & ++ & +++ & ++ & +++ & +++ & - \\
\hline \multirow[t]{7}{*}{ Bacteria } & P. tolaasii & - & - & + & - & - & + & - \\
\hline & P. syringae pv tabaci & - & ++ & ++ & - & - & + & - \\
\hline & P. syringae pv panici & - & ++ & ++ & - & - & + & - \\
\hline & P. cariophilly & - & - & - & - & + & + & - \\
\hline & P. syringae pv syringae & - & + & + & - & - & ++ & - \\
\hline & P. syringae pv japonica & - & ++ & ++ & - & - & + & - \\
\hline & P. syringae pv papulans & - & - & - & - & - & - & ++ \\
\hline
\end{tabular}

No inhibition (-), inhibitory zone $<5 \mathrm{~mm}(+)$, inhibitory zone $5 \mathrm{~mm}(++)$, and inhibitory zone $>5 \mathrm{~mm}(+++)$.

putative UviB-like bacteriocin, were found in strains B. gibsonii RHF15 (Figure 7B) and B. amyloliquefaciens RHFS18 ( 7D-d.1). Their precursor peptides share 42.1 and $33.4 \%$ similarity with UviB.

Finally, Bacillus sp. RHFS10 carries an orphan 28 genes BGC with a core biosynthetic gene encoding a 40-amino acids peptide sharing $35 \%$ of similarity with the competence pheromone of $B$. subtilis 168, a RiPP belonging to class I bacteriocins. Bacillus species are known to synthesize many well-studied bacteriocins, such as subtilin, ericin, paenibacillin, subtilosin, thuricin, and coagulin (Abriouel et al., 2011). Anyway, it is impossible to predict if the six compounds produced by strains B. amyloliquefaciens RHF6, and RHFS18, B. gibsonii RHF15 and Bacillus sp. RHFS10 actually have antimicrobial properties from genome sequence data only. Despite this, the antagonistic activity exerted by RHF6, RHF 15, RHFS10, and RHFS18 strains observed previously in in vitro assays (Table 6) could be associated with these potential compounds. This will need to be validated by further experiments.

\section{CONCLUSION}

In a historic moment in which the increasing population coupled with land degradation aggravates crop production, the use of plant growth promoting bacteria to ensure agricultural productivity has a huge impact on our society. These soil microorganisms enhance plant performance and represent an eco-friendly alternative to chemical fertilizers and pesticides (Hashem et al., 2019). When applied directly to the soil, PGPB enhance plant growth by different action mechanisms such as the production of different phytohormones, accelerating the mineralization of organic matter and improving the bioavailability of the nutrients, and protecting plants from pests' damages. The beneficial activity exerted by PGPB is in part mediated by a broad spectrum of secondary metabolites and enzymes. For example, polyamines, such as spermidine, play important physiological and protective roles in plants, resulting in an increase in biomass, altered root architecture, and elevated photosynthetic capacity. Until recently, these key metabolites were uncovered only by systematic investigation or by serendipity, often understating the PGPB potentiality during their screening. Many genes involved in PGB activity, in fact, could be silent under standard laboratory conditions, due to the absence of appropriate natural triggers or stress signals. More recently, the onset of the genomic era has facilitated the discovery of these ecologically important metabolites and novel strategies became available for PGPR characterization.

For example, genome mining allows to look over the whole genome of a PGPB strain and highlights genes encoding beneficial enzymes, involved in the enhancement of plant nutritional uptake or modulation of hormone levels, as well as for antimicrobial-encoding BGCs.

In this work, we have isolated soil halophilic Bacilli and performed their screening for PGP traits by using standard laboratory procedures and whole-genome analysis. Bacilli represent a significant fraction of the soil microbial community and some species are categorized as PGPB (Cazorla et al., 2007). They are also able to produce endospores, which besides enduring harsh environmental conditions fatal for other cell forms (Petrillo et al., 2020), permit easy formulation and storage of commercial PGPB-based products. In addition, salt-tolerant PGPB can easily withstand several abiotic stresses and ameliorate plant growth in degraded soil.

Seven Bacillus strains have been selected for in vitro PGP traits and identified at the species level by genome analysis. Based on genome mining, not only have we confirmed the beneficial activities PGP found by in vitro analysis, identifying the involved genes but also we have highlighted their strong potentiality by the discovery of novel biosynthesis gene clusters. Our results demonstrated that the genomic analyses, as genome mining, allow a full investigation of PGPB biosynthetic capacity for secondary metabolites and proteins and represent useful tools in the characterization of plant beneficial bacteria. Nevertheless, the divergences observed between the predicted biocontrol functions by found gene clusters and the results obtained by in vitro analysis, highlight the need of combining laboratory-assays and genome-mining in identification of new PGPB for future applications. 


\section{DATA AVAILABILITY STATEMENT}

The datasets presented in this study can be found in online repositories. The names of the repository/repositories and accession number(s) can be found in the article/Supplementary Material.

\section{AUTHOR CONTRIBUTIONS}

RI: conceptualization, supervision, project administration, and funding acquisition. SC and CP: methodology. SC, CP, ML, and MS: validation and formal analysis. SC, CP, and DG: investigation. SC, CP, MS, AC, and RI: data curation. RI, SC, $\mathrm{CP}$, and DG: writing original draft preparation. All authors have read and agreed to the published version of the manuscript.

\section{REFERENCES}

Abriouel, H., Franz, C. M. A. P., Ben Omar, N., and Gálvez, A. (2011). Diversity and applications of Bacillus bacteriocins. FEMS Microbiol. Rev. 35, 201-232. doi: $10.1111 /$ j.1574-6976.2010.00244.x

Agrawal, A. A. (2001). Phenotypic plasticity in the interactions and evolution of species. Science 294, 321-326. doi: 10.1126/science.1060701

Ahmad, M., Zahir, Z. A., Khalid, M., Nazli, F., and Arshad, M. (2013). Efficacy of Rhizobium and Pseudomonas strains to improve physiology, ionic balance and quality of mung bean under salt-affected conditions on farmer's fields. Plant Physiol. Biochem. 63, 170-176. doi: 10.1016/j.plaphy.2012.11.024

Adler, J. (1966). Chemotaxis in Bacteria. Science. 153, 708-716. doi: 10.1126/ science.153.3737.708

Amaya-Gómez, C. V., Porcel, M., Mesa-Garriga, L., and Gómez-Álvarez, M. I. (2020). A framework for the selection of plant growth-promoting rhizobacteria based on bacterial competence mechanisms. Appl. Environ. Microbiol. 86, e00760-e00820. doi: 10.1128/AEM.00760-20

Anwar, U. B., Zwar, I. P., and de Souza, A. O. (2020). "Chapter 12: Biomolecules produced by extremophiles microorganisms and recent discoveries," in New and Future Developments in Microbial Biotechnology and Bioengineering. ed. A. G. Rodrigues (Elsevier), 247-270.

Babalola, O. O. (2010). Beneficial bacteria of agricultural importance. Biotechnol. Lett. 32, 1559-1570. doi: 10.1007/s10529-010-0347-0

Blin, K., Shaw, S., Steinke, K., Villebro, R., Ziemert, N., Lee, S. Y., et al. (2019). antiSMASH 5.0: updates to the secondary metabolite genome mining pipeline. Nucleic Acids Res. 47, W81-W87. doi: 10.1093/nar/gkz310

Bolger, A. M., Lohse, M., and Usadel, B. (2014). Trimmomatic: a flexible trimmer for Illumina sequence data. Bioinformatics 30, 2114-2120. doi: 10.1093/ bioinformatics/btu170

Bunsangiam, S., Sakpuntoon, V., Srisuk, N., Ohashi, T., Fujiyama, K., and Limtong, S. (2019). Biosynthetic pathway of indole-3-acetic acid in basidiomycetous yeast rhodosporidiobolus fluvialis. Mycobiology 47, 292-300. doi: 10.1080/12298093.2019.1638672

Cangiano, G., Mazzone, A., Baccigalupi, L., Isticato, R., Eichenberger, P., De Felice, M., et al. (2010). Direct and indirect control of late sporulation genes by GerR of Bacillus subtilis. J. Bacteriol. 192, 3406-3413. doi: 10.1128/JB. 00329-10

Cangiano, G., Sirec, T., Panarella, C., Isticato, R., Baccigalupi, L., De Felice, M., et al. (2014). The sps gene products affect the germination, hydrophobicity, and protein adsorption of Bacillus subtilis spores. Appl. Environ. Microbiol. 80, 7293-7302. doi: 10.1128/AEM.02893-14

Castaldi, S., Petrillo, C., Donadio, G., Piaz, F. D., Cimmino, A., Masi, M., et al. (2021). Plant growth promotion function of Bacillus sp. strains isolated from salt-pan rhizosphere and their biocontrol potential against macrophomina phaseolina. Int. J. Mol. Sci. 22:3324. doi: 10.3390/ijms22073324

Caulier, S., Nannan, C., Gillis, A., Licciardi, F., Bragard, C., and Mahillon, J. (2019). Overview of the antimicrobial compounds produced by members of the Bacillus subtilis group. Front. Microbiol. 10:302. doi: 10.3389/fmicb.2019.00302

\section{ACKNOWLEDGMENTS}

We thank Marcelo Anibal Carmona (Facultad de Agronomía, Cátedra de Fitopatología, Universidad de Buenos Aires, Buenos Aires, Argentina) for supplying the phytopathogenic fungi (M. phaseolina, C. truncatum, C. nicotianae, and D. teres) used in this study.

\section{SUPPLEMENTARY MATERIAL}

The Supplementary Material for this article can be found online at: https://www.frontiersin.org/articles/10.3389/fmicb.2021.715678/ full\#supplementary-material

Cazorla, F. M., Romero, D., Pérez-García, A., Lugtenberg, B. J. J., de Vicente, A., and Bloemberg, G. (2007). Isolation and characterization of antagonistic Bacillus subtilis strains from the avocado rhizoplane displaying biocontrol activity. J. Appl. Microbiol. 103, 1950-1959. doi: 10.1111/ j.1365-2672.2007.03433.x

Celandroni, F., Vecchione, A., Cara, A., Mazzantini, D., Lupetti, A., and Ghelardi, E. (2019). Identification of Bacillus species: implication on the quality of probiotic formulations. PLoS One 14:e217021. doi: 10.1371/journal. pone.0217021

Cotter, P. D., Ross, R. P., and Hill, C. (2013). Bacteriocins: a viable alternative to antibiotics? Nat. Rev. Microbiol. 11, 95-105. doi: 10.1038/nrmicro2937

Corrado, I., Petrillo, C., Isticato, R., Casillo, A., Corsaro, M. M., Sannia, G., et al. (2021). The power of two: An artificial microbial consortium for the conversion of inulin into Polyhydroxyalkanoates. Int. J. Biol. Macromol. 189, 494-502. doi: 10.1016/.ijbiomac.2021.08.123

Damodaran, T., Sah, V., Rai, R. B., Sharma, D. K., Mishra, V. K., Jha, S. K., et al. (2013). Isolation of salt tolerant endophytic and rhizospheric bacteria by natural selection and screening for promising plant growth-promoting rhizobacteria (PGPR) and growth vigour in tomato under sodic environment. Afr. J. Microbiol. Res. 7, 5082-5089. doi: 10.5897/AJMR2013.6003

Desai, N. C., Makwana, A. H., and Rajpara, K. M. (2016). Synthesis and study of 1,3,5-triazine based thiazole derivatives as antimicrobial agents. J. Saudi Chem. Soc. 20, S334-S341. doi: 10.1016/j.jscs.2012.12.004

Eren, A. M., Kiefl, E., Shaiber, A., Veseli, I., Miller, S. E., Schechter, M. S., et al. (2021). Community-led, integrated, reproducible multi-omics with anvio. Microbiol. 6, 3-6. doi: 10.1038/s41564-020-00834-3

Etesami, H., Mirsyed Hosseini, H., Alikhani, H. A., and Mohammadi, L. (2014). Bacterial biosynthesis of 1-aminocyclopropane-1-carboxylate (ACC) deaminase and indole-3-acetic acid (IAA) as endophytic preferential selection traits by rice plant seedlings. J. Plant Growth Regul. 33, 654-670. doi: 10.1007/ s00344-014-9415-3

Garnier, T., and Cole, S. T. (1988). Complete nucleotide sequence and genetic organization of the bacteriocinogenic plasmid, pIP404, from Clostridium perfringens. Plasmid 19, 134-150. doi: 10.1016/0147-619X(88)90052-2

Giglio, R., Fani, R., Isticato, R., De Felice, M., Ricca, E., and Baccigalupi, L. (2011). Organization and evolution of the cotG and cotH genes of Bacillus subtilis. J. Bacteriol. 193, 6664-6673. doi: 10.1128/JB.06121-11

Glick, B. R., Cheng, Z., Czarny, J., and Duan, J. (2007). Promotion of plant growth by ACC deaminase-producing soil bacteria. Eur. J. Plant Pathol. 119, 329-339. doi: 10.1007/s10658-007-9162-4

Goberna, M., García, C., and Verdú, M. (2014). A role for biotic filtering in driving phylogenetic clustering in soil bacterial communities. Glob. Ecol. Biogeogr. 23, 1346-1355. doi: 10.1111/geb.12227

Gordon, S. A., and Weber, R. P. (1951). Colorimetric estimation of indoleacetic acid. Plant Physiol. 26, 192-195. doi: 10.1104/pp.26.1.192

Gupta, S., and Pandey, S. (2019). ACC deaminase producing bacteria with multifarious plant growth promoting traits alleviates salinity stress in french bean (Phaseolus vulgaris) plants. Front. Microbiol. 10:1506. doi: 10.3389/fmicb.2019. 01506 
Hashem, A., Tabassum, B., and Fathi Abd Allah, E. (2019). Bacillus subtilis: a plant-growth promoting rhizobacterium that also impacts biotic stress. Saudi J. Biol. Sci. 26, 1291-1297. doi: 10.1016/j.sjbs.2019.05.004

Hassan, A. H. A., Alkhalifah, D. H. M., Al Yousef, S. A., Beemster, G. T. S., Mousa, A. S. M., Hozzein, W. N., et al. (2020). Salinity stress enhances the antioxidant capacity of Bacillus and Planococcus species isolated from saline lake environment. Front. Microbiol. 11:561816. doi: 10.3389/ fmicb.2020.561816

Hortal, J., Carrascal, L., Triantis, K., Thébault, E., and Meiri, S. (2013). Species richness can decrease with altitude but not with habitat diversity. Proc. Natl. Acad. Sci. U. S. A. 110, E2149-E2150. doi: 10.1073/pnas.1301663110

Jack, R. W., Tagg, J. R., and Ray, B. (1995). Bacteriocins of gram-positive bacteria. Microbiol. Rev. 59, 171-200. doi: 10.1128/mr.59.2.171-200.1995

Jadhav, H., Shaikh, S., and Sayyed, R. (2017). "Role of hydrolytic enzymes of rhizoflora in biocontrol of fungal phytopathogens: an overview," in Rhizotrophs: Plant Growth Promotion to Bioremediation. ed. S. Mehnaz (Singapore: Springer Singapore) $183-203$.

Jain, C., Rodriguez-R, L. M., Phillippy, A. M., Konstantinidis, K. T., and Aluru, S. (2018). High throughput ANI analysis of $90 \mathrm{~K}$ prokaryotic genomes reveals clear species boundaries. Nat. Commun. 9:5114. doi: 10.1038/s41467-018-07641-9

Jamali, H., Sharma, A., Roohi, and Srivastava, A. K. (2020). Biocontrol potential of Bacillus subtilis RH5 against sheath blight of rice caused by Rhizoctonia solani. J. Basic Microbiol. 60, 268-280. doi: 10.1002/jobm.201900347

Keswani, C., Singh, H. B., García-Estrada, C., Caradus, J., He, Y.-W., Mezaache-Aichour, S., et al. (2020). Antimicrobial secondary metabolites from agriculturally important bacteria as next-generation pesticides. Appl. Microbiol. Biotechnol. 104, 1013-1034. doi: 10.1007/s00253-019-10300-8

Kumar, A., Prakash, A., and Johri, B. (2011). "Bacillus as PGPR in crop ecosystem," in Bacteria in Agrobiology: Crop Ecosystems (Springer Berlin Heidelberg), 37-59.

Li, Z., Chakraborty, P., de Vries, R. H., Song, C., Zhao, X., Roelfes, G., et al. (2020). Characterization of two relacidines belonging to a novel class of circular lipopeptides that act against gram-negative bacterial pathogens. Environ. Microbiol. 22, 5125-5136. doi: 10.1111/1462-2920.15145

Lugtenberg, B., and Kamilova, F. (2009). Plant-growth-promoting rhizobacteria. Annu. Rev. Microbiol. 63, 541-556. doi: 10.1146/annurev.micro.62.081307.162918

O’Toole, G. A. (2011). Microtiter dish biofilm formation assay. J. Vis. Exp. 30:2437. doi: $10.3791 / 2437$

Okada, M., Sato, I., Cho, S. J., Iwata, H., Nishio, T., Dubnau, D., et al. (2005). Structure of the Bacillus subtilis quorum-sensing peptide pheromone ComX. Nat. Chem. Biol. 1, 23-24. doi: 10.1038/nchembio709

Ongena, M., and Jacques, P. (2008). Bacillus lipopeptides: versatile weapons for plant disease biocontrol. Trends Microbiol. 16, 115-125. doi: 10.1016/j. tim.2007.12.009

Pal, K. K., and McSpadden Gardener, B. (2006). Biological control of plant pathogens. Plant Health Instr. 2, 1117-1142. doi: 10.1094/PHI-A-2006-1117-02

Pérez-Miranda, S., Cabirol, N., George-Téllez, R., Zamudio-Rivera, L. S., and Fernández, F. J. (2007). O-CAS, a fast and universal method for siderophore detection. J. Microbiol. Methods 70, 127-131. doi: 10.1016/j.mimet.2007.03.023

Pertot, I., Caffi, T., Rossi, V., Mugnai, L., Hoffmann, C., Grando, M. S., et al. (2017). A critical review of plant protection tools for reducing pesticide use on grapevine and new perspectives for the implementation of IPM in viticulture. Crop Prot. 97, 70-84. doi: 10.1016/j.cropro.2016.11.025

Pesce, G., Rusciano, G., Sasso, A., Isticato, R., Sirec, T., and Ricca, E. (2014). Surface charge and hydrodynamic coefficient measurements of Bacillus subtilis spore by optical tweezers. Colloids Surf. B Biointerfaces 116, 568-575. doi: 10.1016/j.colsurfb.2014.01.039

Petrillo, C., Castaldi, S., Lanzilli, M., Saggese, A., Donadio, G., Baccigalupi, L., et al. (2020). The temperature of growth and sporulation modulates the efficiency of spore-display in Bacillus subtilis. Microb. Cell Factories 19:185. doi: 10.1186/s12934-020-01446-6

Pieterse, C. M. J., Zamioudis, C., Berendsen, R. L., Weller, D. M., Van Wees, S. C. M., and Bakker, P. A. H. M. (2014). Induced systemic resistance by beneficial microbes. Annu. Rev. Phytopathol. 52, 347-375. doi: 10.1146/annurev-phyto-082712-102340

Pikovskaya, R. I. (1948). Mobilization of phosphorus in soil in connection with the vital activity of some microbial species. Mikrobiologiya 17, 362-370.

Reddy, K. R. N., Reddy, C. S., and Muralidharan, K. (2009). Potential of botanical and biocontrol agents on growth and aflatoxin production by
Aspergillus flavus infecting rice grains. Food Control 20, 173-178. doi: 10.1016/j.foodcont.2008.03.009

Rodríguez-Echeverría, S., Lozano, Y. M., and Bardgett, R. D. (2016). Influence of soil microbiota in nurse plant systems. Funct. Ecol. 30, 30-40. doi: 10.1111/1365-2435.12594

Rooney, A. P., Price, N. P. J., Ehrhardt, C., Swezey, J. L., and Bannan, J. D. (2009). Phylogeny and molecular taxonomy of the Bacillus subtilis species complex and description of Bacillus subtilis subsp. inaquosorum subsp. nov. Int. J. Syst. Evol. Microbiol. 59, 2429-2436. doi: 10.1099/ijs.0.009126-0

Schiraldi, C., and De Rosa, M. (2016). "Mesophilic organisms," in Encyclopedia of Membranes. eds. E. Drioli and L. Giorno (Berlin, Heidelberg: Springer Berlin Heidelberg), 1-2.

Schoebitz, M., Ceballos, C., and Ciampi, L. (2013). Effect of immobilized phosphate solubilizing bacteria on wheat growth and phosphate uptake. $J$. Soil Sci. Plant Nutr. 13, 1-10. doi: 10.4067/S0718-95162013005000001

Seemann, T. (2014). Prokka: rapid prokaryotic genome annotation. Bioinformatics 30, 2068-2069. doi: 10.1093/bioinformatics/btu153

Selvakumar, G., Sushil, S. N., Stanley, J., Mohan, M., Deol, A., Rai, D., et al. (2011). Brevibacterium frigoritolerans a novel entomopathogen of Anomala dimidiata and Holotrichia longipennis (Scarabaeidae: Coleoptera). Biocontrol Sci. Tech. 21, 821-827. doi: 10.1080/09583157.2011.586021

Shultana, R., Kee Zuan, A. T., Yusop, M. R., and Saud, H. M. (2020). Characterization of salt-tolerant plant growth-promoting rhizobacteria and the effect on growth and yield of saline-affected rice. PLoS One 15:e0238537. doi: 10.1371/journal.pone.0238537

Sitbon, F., Astot, C., Edlund, A., Crozier, A., and Sandberg, G. (2000). The relative importance of tryptophan-dependent and tryptophan-independent biosynthesis of indole-3-acetic acid in tobacco during vegetative growth. Planta 211, 715-721. doi: 10.1007/s004250000338

van Heel, A. J., de Jong, A., Song, C., Viel, J. H., Kok, J., and Kuipers, O. P. (2018). BAGEL4: a user-friendly web server to thoroughly mine RiPPs and bacteriocins. Nucleic Acids Res. 46, W278-W281. doi: 10.1093/nar/ gky383

Ventosa, A., Nieto, J. J., and Oren, A. (1998). Biology of moderately halophilic aerobic bacteria. Microbiol. Mol. Biol. Rev. 62, 504-544. doi: 10.1128/ MMBR.62.2.504-544.1998

Xie, S.-S., Wu, H.-J., Zang, H.-Y., Wu, L.-M., Zhu, Q.-Q., and Gao, X.-W. (2014). Plant growth promotion by spermidine-producing Bacillus subtilis OKB105. Mol. Plant-Microbe Interact. 27, 655-663. doi: 10.1094/ MPMI-01-14-0010-R

Xu, S. J., and Kim, B. S. (2014). Biocontrol of fusarium crown and root rot and promotion of growth of tomato by paenibacillus strains isolated from soil. Mycobiology 42, 158-166. doi: 10.5941/MYCO.2014.42.2.158

Yoon, S.-H., Ha, S.-M., Lim, J., Kwon, S., and Chun, J. (2017). A large-scale evaluation of algorithms to calculate average nucleotide identity. Antonie Van Leeuwenhoek 110, 1281-1286. doi: 10.1007/s10482-017-0844-4

Zhao, X., and Kuipers, O. P. (2016). Identification and classification of known and putative antimicrobial compounds produced by a wide variety of Bacillales species. BMC Genomics 17:882. doi: 10.1186/s12864-016-3224-y

Conflict of Interest: The authors declare that the research was conducted in the absence of any commercial or financial relationships that could be construed as a potential conflict of interest.

Publisher's Note: All claims expressed in this article are solely those of the authors and do not necessarily represent those of their affiliated organizations, or those of the publisher, the editors and the reviewers. Any product that may be evaluated in this article, or claim that may be made by its manufacturer, is not guaranteed or endorsed by the publisher.

Copyright (c) 2021 Petrillo, Castaldi, Lanzilli, Selci, Cordone, Giovannelli and Isticato. This is an open-access article distributed under the terms of the Creative Commons Attribution License (CC BY). The use, distribution or reproduction in other forums is permitted, provided the original author(s) and the copyright owner(s) are credited and that the original publication in this journal is cited, in accordance with accepted academic practice. No use, distribution or reproduction is permitted which does not comply with these terms. 